\title{
Microscopia de Força Atómica de moléculas de DNA adsorvidas na superfície de HOPG
}

\author{
A. M. CHIORCEA PAQUIM E A. M. OLIVEIRA BRE T T*
}

\section{Resumo}

A microscopia de força atómica (AFM) foi utilizada no estudo dos processos de adsorção da base purínica guanina, de ácidos nucleicos de hélice dupla (dsDNA) e de hélice simples (ssDNA), na superfície de eléctrodos de grafite pirolítica altamente orientada (HOPG). A adsorção na superfície de HOPG, a partir de soluções saturadas de guanina, determinou a formação de múltiplas camadas moleculares estáveis e resistentes. Métodos electroquímicos de adsorção permitiram a condensação da guanina, conjuntamente com dímeros, trímeros e outros produtos de oxidação, formando filmes espessos, heterogéneos, menos compactos e resistentes. As imagens de AFM de ssDNA e de dsDNA, imobilizados na superfície de HOPG, mostraram a tendência das moléculas para uma auto-organização espontânea na superfície. Os ácidos nucleicos condensaram-se em redes bidimensionais densas, exten- sas, cobrindo uniformemente toda a superfície. A interacção com a superfície de HOPG hidrofóbica induziu sobreposições de moléculas e interacções intra e intermoleculares. A aplicação de um potencial positivo ao eléctrodo de HOPG durante a adsorção aumentou a robustez e a estabilidade mecânica dos filmes de DNA, devido a múltiplas interacções electrostáticas estabelecidas entre o esqueleto de açúcar-fosfato do DNA negativamente carregado e a superfície carregada positivamente. As características estruturais, a espessura, a sobreposição das moléculas da rede e o grau de cobertura da superfície dependiam da concentração, do pH e do método de imobilização utilizado.

Keywords: DNA, AFM, adsorção, biossensor electroquímico com DNA.

\section{Introdução}

Os ácidos nucleicos, nomeadamente 0 ácido desoxiribonucleico (DNA) e o ácido ribonucleico (RNA), são macromoléculas biológicas de extrema relevância que possuem propriedades químicas e biofísicas muito importantes [1]. O DNA tem um papel fundamental na determinação das características hereditárias, dado que armazena a informação genética necessária à génese dos organismos vivos, transmitindo-a às gerações seguintes. Devido às suas características de reconhecimento e interligação com outras moléculas pela complementaridade e emparelhamento das suas bases, os ácidos nucleicos têm sido usados na construção de novos dispositivos em nanotecnologia [2, 3]. A capacidade de adsorção interfacial dos ácidos nucleicos, bem como das bases, nucleótidos e nucleósidos que entram na sua composição, tem várias aplicações na tecnologia dos biossensores, com diversos usos em biotecnologia e medicina [4-6].

Os biossensores são dispositivos que incluem um receptor e um sensor. Os biossensores com DNA utilizam os ácidos nucleicos como agente biológico de reconhecimento, para detectar compostos químicos, normalmente por intermédio de um sensor eléctrico, térmico ou químico. Os biossensores electroquímicos com DNA receberam uma atenção especial, dada a sua aplicação na detecção dos danos no DNA em diagnósticos clínicos, no controlo de qualidade dos alimentos, na detecção dos agentes poluentes no meio ambiente, na investigação da interacção dos fármacos com o DNA e na monitorização directa dos processos de hibridização [4-6].

A imobilização e estabilização das moléculas de ácidos nucleicos na superfície do sensor electroquímico (o eléctrodo) é de grande importância na construção de um biossensor electroquímico com DNA. O fenómeno de adsorção de DNA na superfície de eléctrodos sólidos permite a modificação das propriedades químicas e estruturais do sensor e apresenta uma importância fundamental na compreensão de muitos processos fisiológicos.

A natureza específica das interacções das moléculas de DNA com a superfície dos eléctrodos, as diferentes estruturas e conformações que o DNA pode adoptar durante o processo de imobilização, a morfologia e o grau de cobertura da superfície do eléctrodo têm vindo a ser

*Endereço para correspondência: Ana Maria Oliveira Brett

Departamento de Química, Faculdade de Ciências e Tecnologia, Universidade de Coimbra, 3004-535 Coimbra, Portugal e-mail: brett@ ci.uc.pt, Tel/Fax:+351-239-835295 
figura 1 Esquema do princípio de funcionamento do: (A) microscópio de força atómica (AFM) e (B) modo magnético de corrente alterna de AFM (Modo MAC de AFM).
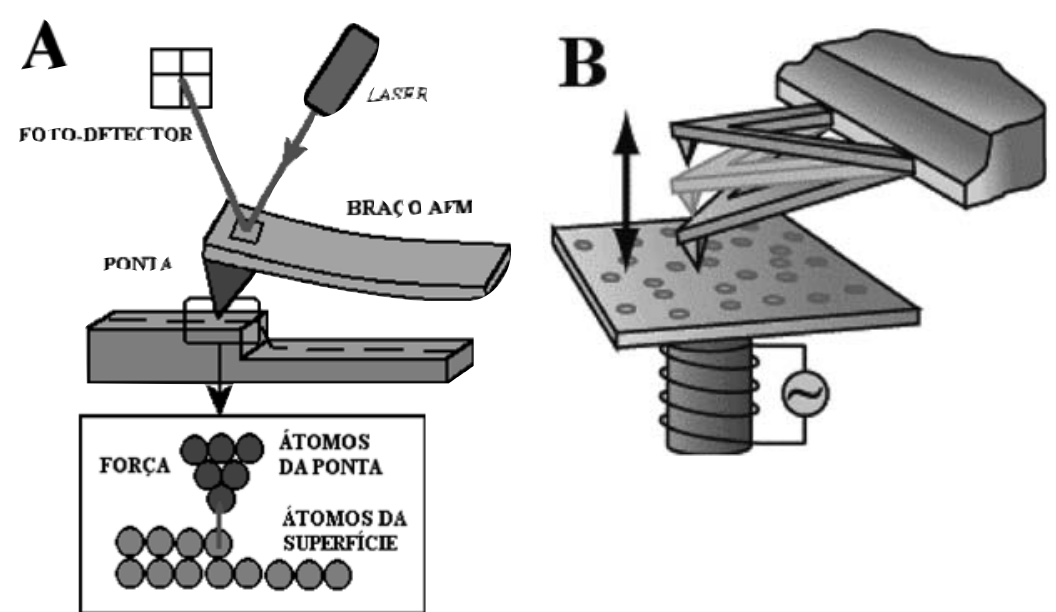

atómico e molecular a topografia das superfícies sólidas [7-9]. A microscopia de túnel de varrimento (STM - Scanning Tunneling Microscopy) e a microscopia de força atómica (AFM - Atomic Force Microscopy) permitem a observação das amostras tanto em ar como em solução, possibilitando o estudo das amostras biológicas num meio ambiente muito mais real, mantendo a hidratação das moléculas.

Os eléctrodos de carbono, como por exemplo o carbono vítreo, as fibras de carbono, a pasta de carbono ou diferentes formas de grafite, possuem normalmente um intervalo de potencial útil bastante largo, em especial para os valores de potencial positivo, o que permite a detecção dos danos oxidativos causados ao DNA, através da obtenção dos picos de oxidação das bases purínicas guanina e adenina [4-6]. A investigação por AFM da adsorção de moléculas de DNA imobilizadas em substratos condutores de carbono, necessárias em aplicações electroquímicas, é de grande importância para o esclarecimento da morfologia adoptada por estas molécu- las imobilizadas na superfície dos biossensores electroquímicos com DNA.

Neste contexto, este trabalho mostra os resultados obtidos utilizando o AFM no estudo dos processos de adsorção, nucleação e crescimento de filmes moleculares de mono e múltiplas camadas, constituídas pela base guanina ou por DNA, na superfície dos eléctrodos sólidos de grafite pirolítica altamente orientada (HOPG - highly oriented pyrolytic graphite), em condições electroquimicamente controladas, com o objectivo da caracterização morfológica da superfície, construção e melhoria da especificidade e sensibilidade dos biossensores electroquímicos com DNA.

\section{Microscopia de Força Atómica (AFM)}

A microscopia de força atómica (AFM) é uma técnica desenvolvida por Binning, Quate e Gerber em 1986, como resultado de uma colaboração entre a IBM e a Universidade de Stanford, e que permite obter imagens reais, em três dimensões, da topografia das superfícies, com figura 2 Imagem topográfica do eléctrodo de HOPG, obtida em ar, com AFM de contacto, mostrando resolução atómica do substrato, com o arranjo hexagonal dos átomos de carbono. (A) Imagem original não tratada. (B) Imagem em três dimensões de A, modificada por um processamento digital, após a sua aquisição, que consiste numa filtragem utilizando a transformada de Fourier, passando apenas as frequências correspondentes aos átomos e associadas com a topografia da superfície.
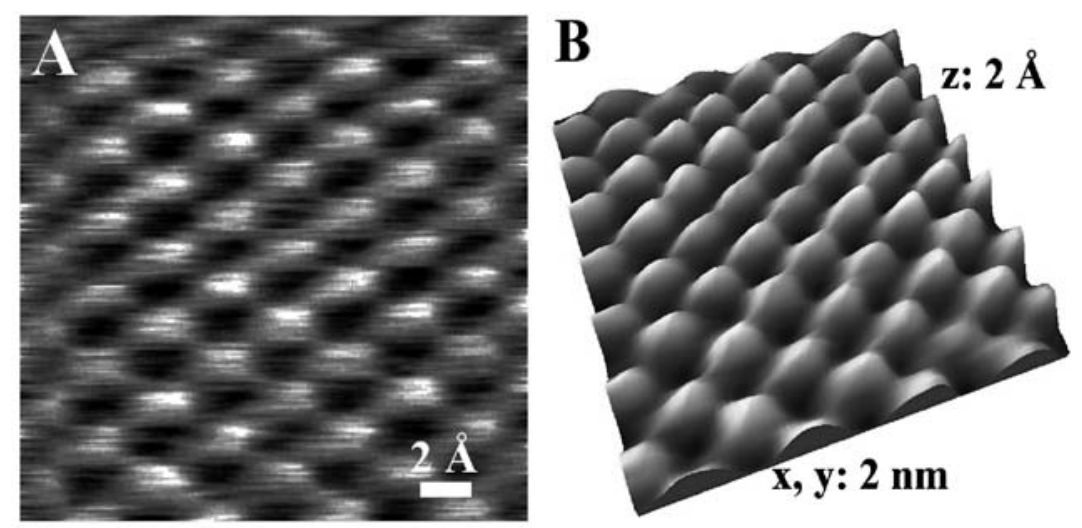
uma resolução espacial que se aproxima das dimensões atómicas [7-9]. O microscópio de força atómica permite a caracterização das propriedades interfaciais dos eléctrodos, possibilitando a observação directa da arquitectura da superfície. Consequentemente, a técnica de AFM pode trazer informações importantes sobre a morfologia da superfície dos eléctrodos modificados com moléculas biológicas.

Em AFM é efectuado o varrimento da superfície da amostra utilizando uma sonda sensível à força (sensor de força), que consiste numa ponta de dimensões atómicas integrada num braço em movimento, figura 1A. À medida que a ponta se aproxima da superfície, os átomos da ponta interagem com os átomos e as moléculas da superfície do material, causando a deflexão do braço de AFM. Esta deflexão do braço de AFM é medida através da mudança de direcção (angular) de um feixe laser emitido por um díodo de estado sólido e reflectido pelo braço de AFM, sendo o feixe laser reflectido captado por um fotodetector de fendas. A sonda de AFM segue os contornos da superfície. Durante a deslocação da ponta pela superfície o computador ana- lisa, em cada posição na superfície, a força de interacção entre a ponta de AFM e a amostra e traça o diagrama das alturas, construindo a topografia da amostra.

O modo magnético de corrente alterna de AFM (modo MAC de AFM - Magnetic AC Mode AFM) é uma nova técnica de AFM desenvolvida para a investigação de moléculas biológicas frágeis. Em modo MAC de AFM é induzida uma oscilação no braço AFM, com uma frequência perto da sua frequência de ressonância [10], por intermédio de um campo magnético controlado por um solenóide colocado por baixo do suporte da amostra,
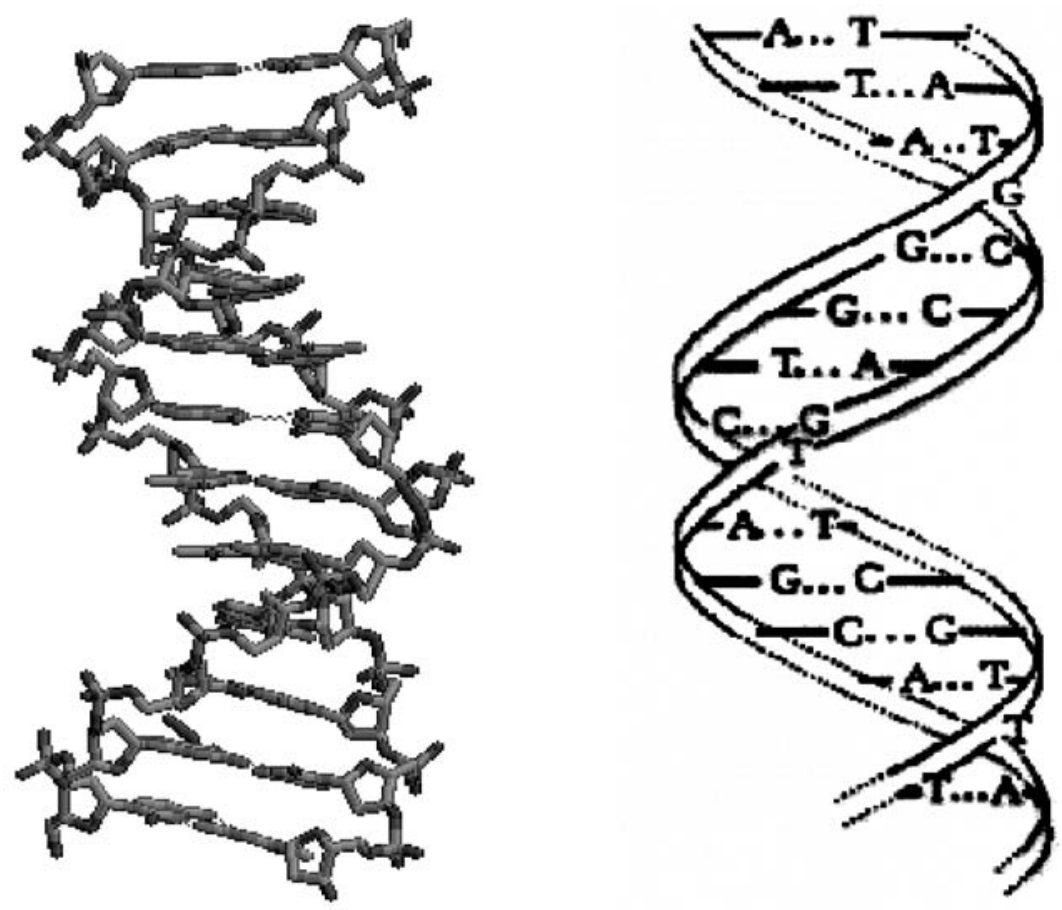

figura 3. Representação esquemática do B-DNA

figura 1B. Durante o varrimento da amostra, o braço de AFM mantém o movimento oscilatório, tocando a amostra apenas uma vez em cada ciclo de oscilação, diminuindo a interacção com a superfície e minimizando os danos provocados nas amostras biológicas.

Para ser possível efectuar a investigação por técnicas de microscopia, as moléculas biológicas devem ser imobilizadas na superfície de um substrato sólido muito plano, com resolução atómica. O substrato de HOPG apresenta uma estrutura atomicamente plana, inerte em ar, fácil de limpar, com uma morfologia homogénea e ordenada à escala atómica com um ar- ranjo regular e periódico dos átomos, figura 2. Por esta razão, o eléctrodo de HOPG representa uma óptima escolha para a investigação do processo de adsorção do DNA, de modo a estudar a adsorção, nucleação e crescimento de agregados de DNA na superfície de um biossensor electroquímico com DNA [11-13].

No entanto, as moléculas de DNA interagem de maneira fraca com a superfície do substrato de HOPG e a ponta de AFM tende a limpar a superfície, varrendo as moléculas adsorvidas para as margens dos degraus do substrato de grafite. Consequentemente, a utilização do modo MAC de AFM em condições electroquimicamente controladas é imprescindível para a investigação do processo de imobilização de moléculas de dsDNA, de ssDNA e da natureza da interacção destas moléculas com a superfície do eléctrodo de HOPG [14-16].

\section{Estrutura do DNA}

O DNA é um polímero linear, constituído por quatro unidades monoméricas denominadas nucleótidos [1]. Cada nucleótido é composto por três fragmentos moleculares: um açúcar, uma base heterocíclica e um agrupamento fosfato. As partes açúcar-fosfato representam a 
figura 4 Estruturas pouco usuais de DNA que se podem formar localmente, no interior da molécula de DNA [16]: (A) cadeias simples; (B) estrutura desalinhada; (C) DNA cruciforme; (D) estrutura dupla paranémica; (E) estrutura alternante B-DNA e Z-DNA; (F) forma V; (G) estrutura com cabeça de alfinete CA; (H) G-DNA; (I) DNA hélice tripla. espinha dorsal dos ácidos nucleicos com função apenas estrutural. As bases purínicas, adenina e guanina, e as bases pirimidínicas, citosina e timina, entram na constituição do DNA e codificam a informação genética celular, em função da proporção e respectiva ordem consecutiva, existente ao longo da cadeia polinucleotídica.

O modelo tridimensional do DNA proposto em 1953, por James Watson e Francis Crick [14], descreve a estrutura da forma B do DNA (B-DNA), figura 3. 0 B-DNA apresenta duas cadeias de polinucleótidos complementares enroladas ao longo de um eixo comum, formando uma hélice dupla. A característica essencial deste modelo é o facto das bases do DNA estarem empacotadas no interior da hélice dupla, com as unidades fosfato e desoxirribose na parte exterior [15]. As bases ficam ligadas por pontes de hidrogénio, a adenina forma com a timina duas pontes de hidrogénio e a guanina forma com a citosina três pontes de hidrogénio. Interacções hidrofóbicas e ligações de van der Waals contribuem também para a estabilidade da dupla hélice.

No entanto, os polinucleótidos são moléculas extremamente flexíveis, com uma grande capacidade de adoptar várias configurações estruturais, em função da sequência, concentração de iões, temperatura e humidade relativa [1] originando, entre outras, as conformações

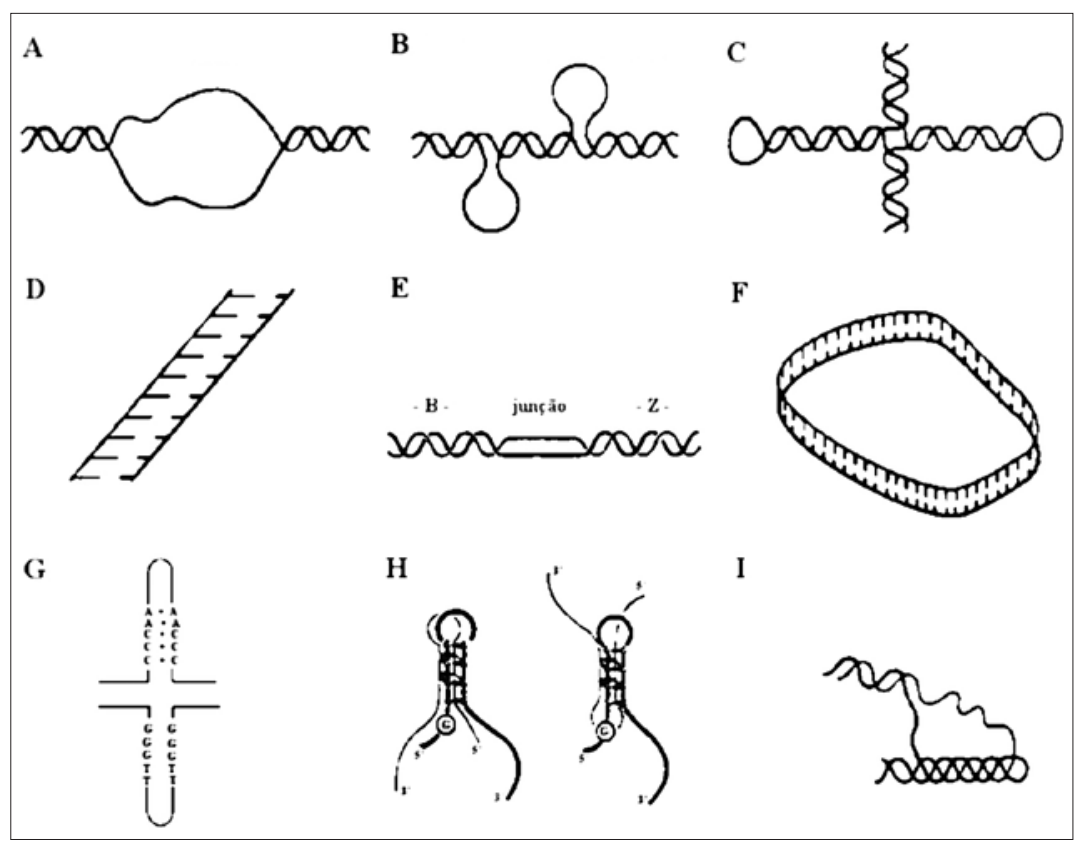

denominadas de estruturas A-DNA e ZDNA. Estruturas pouco usuais de DNA, que se podem formar localmente, no interior da molécula de DNA [16] estão esquematizadas na figura 4.

Além da estrutura secundária de dupla hélice, o DNA assume conformações tridimensionais superhelicoidais (super hélice), definidas como enrolamentos das duplas hélices sobre si mesmas. Deformação e formação de super hélices do DNA circular ou linear aparecem durante a replicação, transcrição e ligação com várias proteínas.

\section{Microscopia de força atómica da adsorção da guanina}

A guanina adsorve espontaneamente na superfície de HOPG, por intermédio de interacções não covalentes, tais como ligações hidrofóbicas, pontes de hidrogénio e forças de van der Waals, formando múltiplas camadas moleculares. O processo de adsorção da guanina na superfície do eléctrodo de HOPG e a formação de filmes moleculares espessos foram observados dentro da solução de guanina, com o modo MAC de AFM, utilizando a adsorção em condições electroquimicamente controladas.

As imagens topográficas obtidas em solução de guanina indicaram que as moléculas adsorviam de modo rápido e espontâneo na superfície de HOPG, formando uma cobertura da superfície extremamente compacta. O procedimento electroquímico de adsorção influenciou o processo de nucleação e crescimento das moléculas de guanina adsorvidas na superfície do eléctrodo de HOPG [17, 18]. As imagens de AFM mostraram que a guanina condensou, formando núcleos mais largos, com 10-30 nm de altura e de 90 a $150 \mathrm{~nm}$ de largura, a meia altura, figura 5B. Os núcleos ficavam agrupados em cadeias semelhantes a estruturas poliméricas, de diferentes tamanhos, algumas maiores que $1 \mu \mathrm{m}$, intercaladas e entrecruzadas umas com as outras e distribuídas uniformemente na superfície de HOPG.

Além de ser uma molécula importante na constituição dos ácidos nucleicos, a base purínica guanina, figura $5 \mathrm{~A}$, desempenha também outras funções biológicas. A guanina é oxidada mais facilmente do que as outras bases do DNA (a purína adenina, e as pirimidínas timina e citosina), apresentando o potencial de oxidação mais baixo nas mesmas condições experimentais [4, 19]. Os estudos electroquímicos demonstraram que a guanina é oxidada irreversivelmente na posição $\mathrm{C} 8-\mathrm{H}$, por um mecanismo em dois passos, cada um envolvendo a perda de electrões e protões. O principal produto de oxidação da guanina é a 8oxoguanina, que é também electroactiva, mutagénica e um biomarcador dos danos oxidativos no DNA e do stress oxidativo [20]. A 8-oxoguanina é oxidada a 
+ 0,45 V, num valor de potencial bastante inferior ao valor da guanina, e os seus produtos de oxidação sofrem rapidamente hidrólise para a solução. Os estudos electroquímicos da guanina em soluções saturadas mostraram também a formação de dímeros, figura 5E, e trímeros, entre os produtos de oxidação.

As moléculas de guanina adsorvem na superfície de HOPG em conjunto com estes produtos de oxidação, constituindo as cadeias observadas nas imagens de AFM, figura $5 B$.

Com o objectivo de determinar a estabilidade do filme formado com o método de adsorção assistida por electroquími$\mathrm{ca}$, foi efectuado, simultaneamente com a imagem de AFM, um voltamograma cíclico na solução saturada de guanina. As modificações das características do filme de guanina foram analisadas durante o processo de aquisição das imagens de AFM, figura 5, em paralelo com o varrimento electroquímico entre $0 \mathrm{e}$ $+1,3 \mathrm{~V}$. Foi possível constatar que, no intervalo de potencial de $0 \mathrm{a}+0,75 \mathrm{~V}$, o filme de guanina permaneceu completamente estável na superfície de HOPG. Para o potencial de oxidação da guanina de $+0,75 \mathrm{~V}$, foram observadas mudanças radicais no filme de guanina. Aumentando o potencial além do valor de $+0,9 \mathrm{~V}$, as cadeias existentes nas imagens de AFM foram dissolvidas por completo da superfície do eléctrodo de HOPG, devido à hidrólise dos produtos de oxidação da 8-oxoguanina formada, figura 5D. Na superfície de HOPG, foram observados os dímeros e os trímeros de guanina, adsorvidos fortemente, figura $5 F$, e também identificados por electroquímica.

Os filmes moleculares de guanina adsorvida na superfície de HOPG, em conjunto com os seus produtos de oxidação obtidos electroquímicamente, mostraram-se menos estáveis na superfície, do que os filmes de guanina obtidos por adsorção espontânea. Este fenómeno deve-se provavelmente a uma menor interacção existente entre as diferentes moléculas envolvidas na adsorção e à orientação destas moléculas na superfície de HOPG.

A investigação das estruturas e da morfologia das múltiplas camadas de guanina, adsorvida nas superfícies de substratos sólidos com métodos electroquímicos de adsorção, contribuiu para a compreensão do mecanismo de adsorção e da natureza das interacções destas moléculas com a superfície carregada do eléctrodo.

\section{Adsorção espontânea de dsDNA e ssDNA na superfície de HOPG}

A adsorção espontânea de DNA na superfície do eléctrodo de HOPG representa um processo muito simples de imobi-

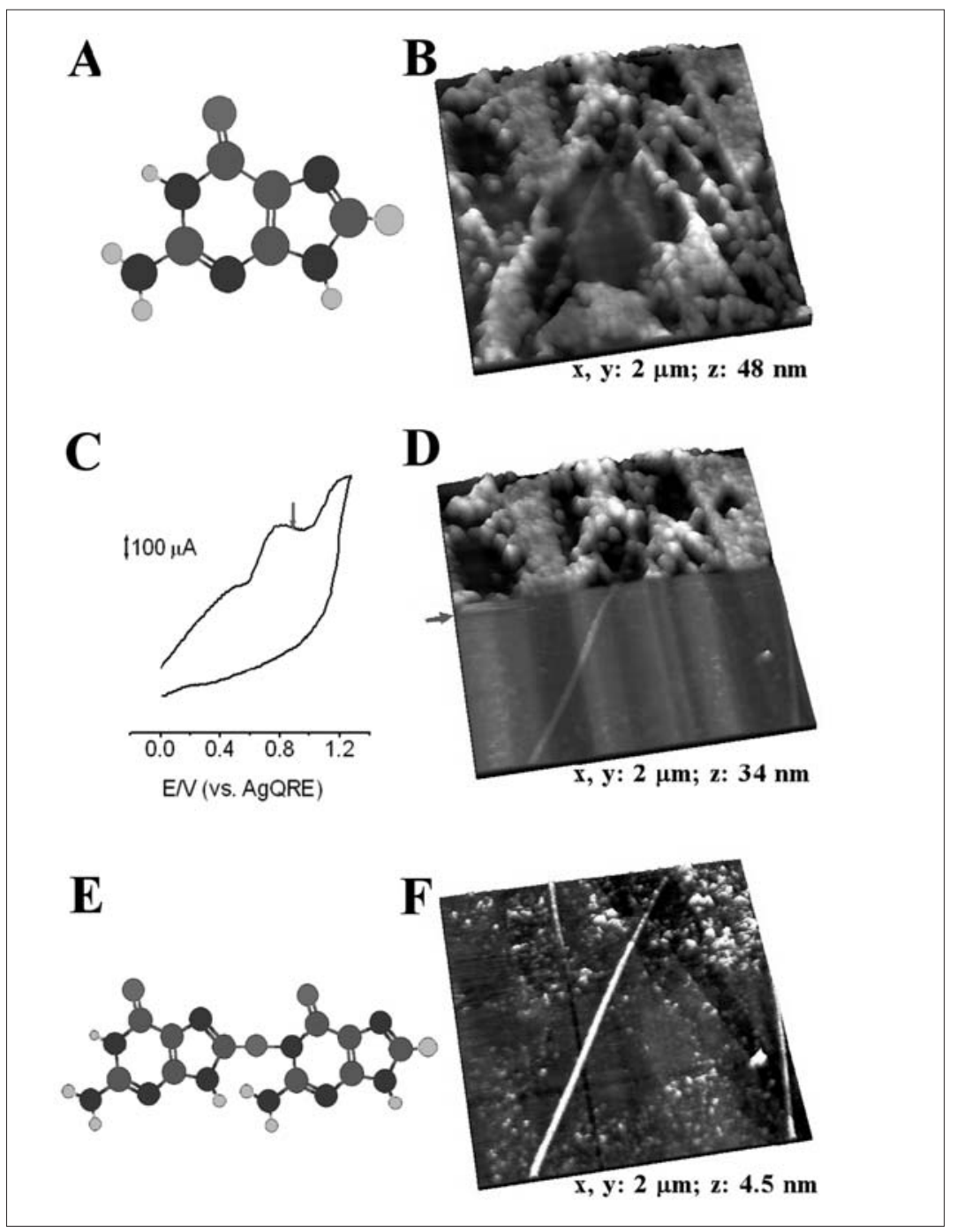

figura 5 (A) Estrutura da molécula de guanina. (B, D, F) Sequência de três imagens topográficas sucessivas, obtidas na solução saturada $10^{-3} \mathrm{M}$ de guanina em electrólito tampão acetato 0,2 M, pH 4,5, com o modo MAC de AFM. As imagens mostram a dissolução do filme de guanina preparado na superfície de HOPG utilizando um procedimento electroquímico, sendo as imagens registadas (B) antes, (D) durante e (F) depois de efectuar o voltamograma cíclico (C). (C) Voltamograma cíclico de 0 a 1,3 V, us. $\mathrm{AgQRE}$, velocidade de varrimento $0,1 \mathrm{~V} \mathrm{~s}^{-1}$, registado durante o varrimento de AFM. (E) Modelo esquemático de um dímero da guanina 
figura 6 Imagens topográficas de dsDNA, obtidas em ar, com o modo MAC de AFM. O dsDNA foi imobilizado na superfície de HOPG, por adsorção espontânea durante $3 \mathrm{~min}$, a partir duma solução de $1 \mu \mathrm{g} / \mathrm{mL}$ dsDNA em: (A) electrólito tampão fosfato 0,1 M, pH 7,0; (B) água.

lização de DNA na superfície dos eléctrodos, pois não envolve nenhuma modificação química do DNA nem da superfície do eléctrodo. $O$ eléctrodo de HOPG foi modificado com um filme fino de dsDNA ou de ssDNA, formado por adsorção espontânea, a partir de soluções de diferentes concentrações de DNA em electrólito tampão. A caracterização da morfologia da superfície do eléctrodo de HOPG, modificado com moléculas de dsDNA e ssDNA imobilizadas por adsorção espontânea, é extremamente importante na preparação de biossensores electroquímicos com DNA, e foi investigada em ar, com o modo MAC de AFM.

\section{Adsorção espontânea de dsDNA}

As imagens topográficas de dsDNA, imobilizado no eléctrodo de HOPG a partir de soluções de muito baixa concentração, mostraram que as moléculas de dsDNA adsorvem espontaneamente na superfície do eléctrodo, figura 6 , sendo a adsorção muito rápida. As moléculas formaram estruturas enroladas e torcidas, numa extensão larga de superfície. Contudo, as moléculas de dsDNA que se encontram adsorvidas no eléctrodo de HOPG estão fortemente desidratadas, adoptando a forma A-DNA. A altura das moléculas de dsDNA obtidas com o AFM em estudos em ar varia entre $0,5 \mathrm{~nm}$ e $1,9 \mathrm{~nm}$ [21], valores que são geralmente muito inferiores ao diâmetro real de $\sim 2,6 \mathrm{~nm}$ da forma A-DNA [1].

As partes lineares de dsDNA permitiram a determinação das dimensões das moléculas de dsDNA imobilizadas na superfície de HOPG. As alturas das moléculas, calculadas em secções transversais nas imagens, correspondem
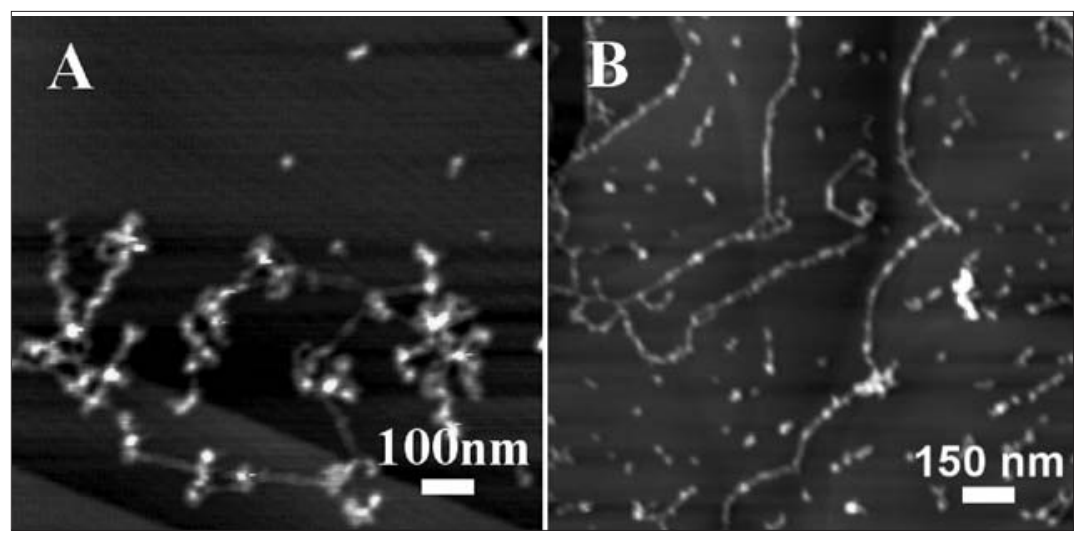

duma maneira mais precisa ao verdadeiro diâmetro do dsDNA, e a altura média e o desvio padrão do dsDNA foi de $0,7 \mathrm{~nm} \pm 0,2 \mathrm{~nm}$.

A adsorção espontânea de dsDNA sobre a superfície de HOPG foi também estudada, utilizando soluções mais concentradas de dsDNA, que variaram entre 5 e $60 \mu \mathrm{g} / \mathrm{mL}$, figura 7A. Foi observado, como esperado, um progressivo aumento do grau de cobertura e foi possível seguir o crescimento da rede bidimensional de dsDNA, espalhada por toda a superfície do eléctrodo. A adsorção na superfície de HOPG mostrou um filme reticular de dsDNA que apresentava poros, correspondentes às regiões escuras na imagem, e exibindo no fundo dos poros a superfície de HOPG situada por debaixo. O contorno do filme ao longo da rede de dsDNA foi ligeiramente irregular. As análises por secção, realizadas em diferentes imagens, permitiram a construção do gráfico de distribuição da espessura do filme, figura 7B, mostrando valores para duas alturas típicas, $0,99 \mathrm{~nm} \pm 0,25 \mathrm{~nm}$ e $2,15 \mathrm{~nm} \pm 0,25$ $\mathrm{nm}$. As maiores alturas podem estar associadas a estruturas mais complexas, em consequência de fenómenos de agregação do dsDNA e da sobreposição de moléculas, que conduzem à formação de múltiplas camadas moleculares.

O dsDNA é uma molécula hidrofílica, devido aos grupos fosfato existentes no exterior da hélice, dando origem a uma carga negativa elevada ao longo da dupla hélice. Em teoria, estas características particulares deviam reduzir a interacção espontânea com a superfície hidrofóbica de HOPG. Em solução, as extremidades da hélice dupla de dsDNA não são estáticas e ocorre uma associa- ção-dissociação contínua das bases complementares existentes nas cadeias da molécula, expondo esporadicamente as bases hidrofóbicas [1]. A molécula de dsDNA adsorve assim na superfície de HOPG, por intermédio de múltiplas interacções hidrofóbicas entre a superfície hidrofóbica de HOPG e os anéis hidrofóbicos das bases existentes nas extremidades livres do dsDNA.

$\mathrm{Na}$ interface sólido-líquido, o ambiente do dsDNA difere de maneira substancial do ambiente no interior da solução. 0 dsDNA é uma molécula extremamente flexível, e pode apresentar várias conformações estruturais na superfície do eléctrodo [11, 12]. No dsDNA com uma cadeia longa, a probabilidade de encontrar sequências repetidas é muito elevada e a grande variedade de sequências origina uma grande variedade de estruturas possíveis, adoptadas pelo dsDNA na superfície de HOPG.

\section{Adsorção espontânea de ssDNA}

As imagens topográficas de SSDNA, imobilizado no eléctrodo de HOPG, mostraram que as moléculas condensavam na superfície em grandes agregados de moléculas enroladas, figura 8A. 0 aumento da concentração levou à formação duma rede incompleta de ssDNA, auto-organizada em duas dimensões, com poros que deixavam descoberta a superfície do eléctrodo, figura 8B.

As moléculas de ssDNA genômico têm uma cadeia com muitos pares de bases e adoptam, em solução, configurações flexíveis semelhantes aos polímeros, com partes formando hélice dupla, devido a fenómenos de hibridização espontânea das zonas que apresentam aleatoriamente bases complementares. No 

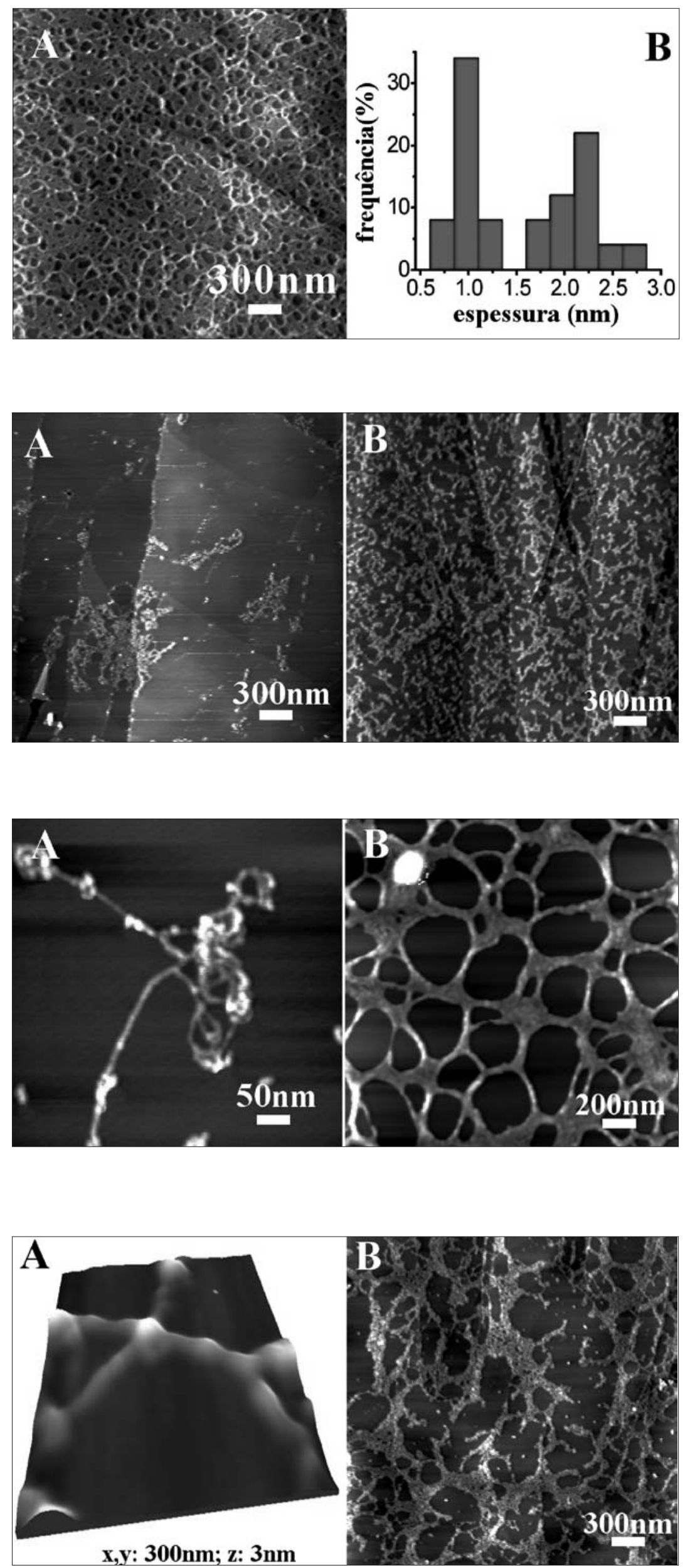

figura 10 Imagens topográficas de ssDNA, obtidas em ar, com o modo MAC de AFM. O ssDNA foi imobilizado na superfície de HOPG, aplicando um potencial de adsorção de +300 $m V$, us. AgQRE, durante $3 \mathrm{~min}$, ao eléctrodo mergulhado numa solução em electrólito tampão fosfato 0,1 M, pH 7,0 de ssDNA: (A) $1 \mu \mathrm{g} / \mathrm{mL}$ (B) $5 \mu \mathrm{g} / \mathrm{mL}$ 
figura 11 Imagens topográficas de dsDNA, obtidas em ar, com o modo MAC de AFM. O dsDNA foi imobilizado na superfície de HOPG, por adsorção durante $3 \mathrm{~min}$, a partir duma solução de $60 \mu \mathrm{g} / \mathrm{mL}$ dsDNA em electrólito suporte de 0,1 M: (1) adsorção espontânea: (A) tampão acetato $\mathrm{pH}$ 5,3 e (B) tampão fosfato $\mathrm{pH} 7,0$; (2) adsorção com potencial de $+300 \mathrm{mV}$, us. AgQRE: (C) tampão acetato pH 5,3 e (D) tampão fosfato $\mathrm{pH}$ 7,0.
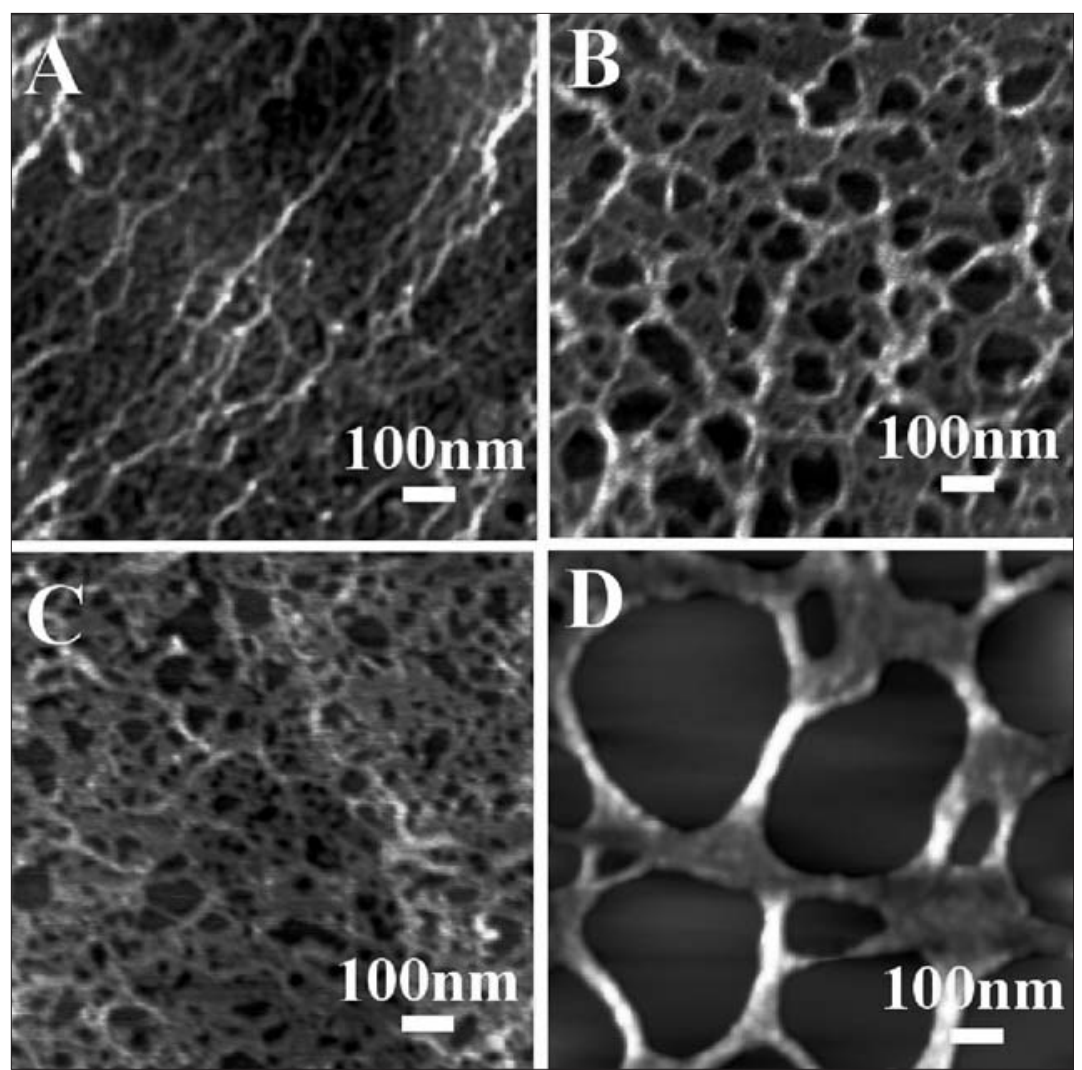

efectuada a adsorção do DNA em condições electroquimicamente controladas. O eléctrodo carregado positivamente exerce uma atracção electrostática sobre a estrutura açúcar-fosfato dos ácidos nucleicos, carregada negativamente. A adsorção de moléculas de DNA na superfície do eléctrodo de HOPG foi conseguida aplicando ao eléctrodo um potencial de $+300 \mathrm{mV}$, valor escolhido de modo a não ser demasiado elevado para oxidar as bases do DNA [4-6], sendo no entanto suficiente para atrair as moléculas para a superfície. Durante as experiências de AFM realizadas, foram investigadas as características topográficas do eléctrodo de HOPG modificado por filmes finos e secos de dsDNA e SsDNA.

\section{Adsorção de dsDNA com potencial aplicado}

As moléculas de dsDNA adsorvidas com potencial aplicado, figura 9A, apresentaram uma estabilidade superior na superfície de HOPG, quando comparada com os resultados obtidos com o dsDNA adsorvido espontaneamente a partir de uma solução da mesma concentração. $\mathrm{O}$ dsDNA apresentava um grande número de cruzamentos intramoleculares e as regiões de cadeias em colapso coexis- tiam com cadeias estreitas. Foram observados agregados esféricos com dimensões entre 1,7 nm e $4 \mathrm{~nm}$ ao longo das cadeias de hélice dupla, provavelmente em forma A-DNA, com a altura de $1,1 \mathrm{~nm} \pm 0,2 \mathrm{~nm}$.

As imagens do eléctrodo de HOPG modificado, a partir duma solução concentrada de dsDNA, mostraram a formação duma rede bidimensional, distribuída por toda a superfície de maneira uniforme, figura 9B. As redes de dsDNA eram constituídas por fibras enroladas e unidas, formadas devido à agregação das extremidades livres das moléculas que as estabilizavam na superfície do eléctrodo de HOPG. As moléculas de dsDNA condensaram em conjuntos torcidos, formando cruzamentos largos e flexíveis. Partes extensas da superfície não ficaram cobertas pela malha de dsDNA.

A espessura do filme, medida ao longo dos cruzamentos da rede, foi muito irregular, com alturas a variar desde $3,5 \mathrm{~nm}$ até $7,5 \mathrm{~nm}$. Os valores obtidos foram muito superiores aos valores que se esperavam para o dsDNA em forma A-DNA, sugerindo que no processo de condensação estavam envolvidas várias camadas de moléculas de dsDNA. 


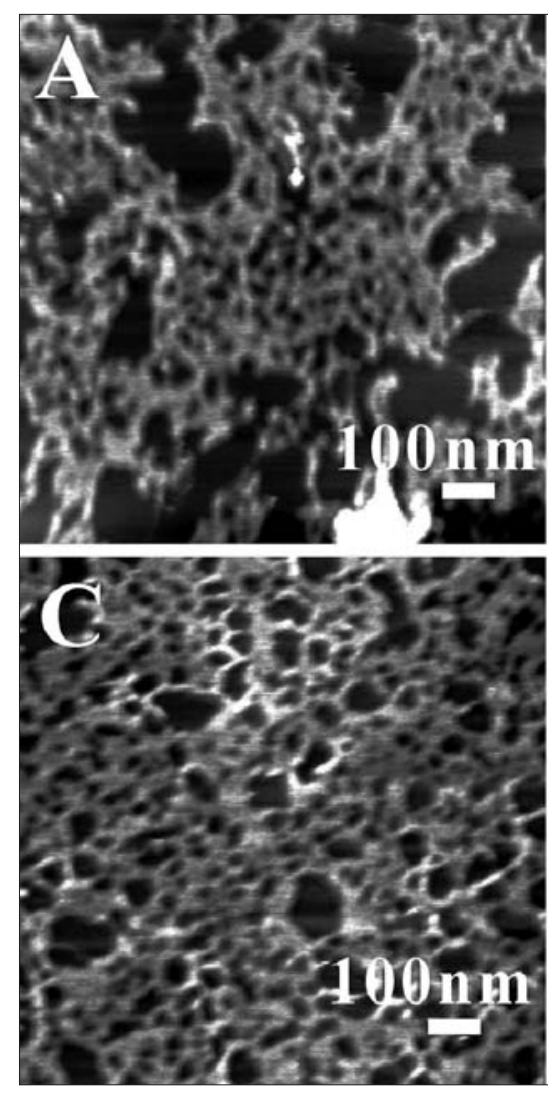

Em conclusão, o potencial aplicado ao eléctrodo de HOPG aumentou a interacção lateral atractiva entre as hélices adjacentes de dsDNA, causando uma condensação espontânea e uma agregação lateral forte das moléculas de dsDNA na superfície de HOPG e formando uma rede complexa. A estabilidade do filme na superfície aumentou consideravelmente em consequência desta interacção electrostática com a superfície de HOPG carregada positivamente, mas o filme ainda apresentava os poros até à superfície do eléctrodo de HOPG.

\section{Adsorção de ssDNA com potencial aplicado}

A imobilização de forma estável de ssDNA na superfície de eléctrodos é muito importante, especialmente nos estudos de detecção de fenómenos de hibridização. A adsorção espontânea mostrou que as moléculas tinham tendência a formar grandes agregados, figura 8A. No entanto, em condições electroquimicamente controladas, a agregação das moléculas foi completamente evitada e pôde ser observada a formação duma rede bidimensional constituída pelas cadeias simples individuais, alastrando por toda a superfície de HOPG. Este resulta-

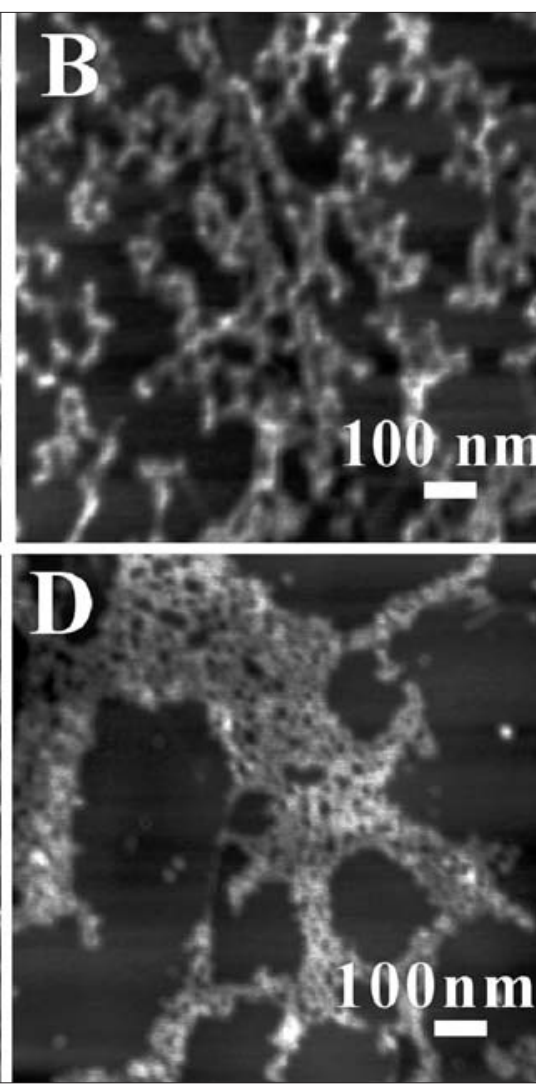

do sugere que, no caso do SSDNA, a adsorção com potencial aplicado é muito eficiente. As cadeias da rede formavam ângulos variados, figura 10A, e tanto nos pontos de confluência das bifurcações como ao longo dos segmentos lineares foi observada a aparição de conglomerados globulares.

A agregação ocorreu por meio de partes de moléculas entrelaçadas e entrecruzadas, ou pela condensação e interacção das hélices simples, no momento da formação da rede. É muito provável que partes das hélices simples apresentem sequências de bases complementares, hibridizando com outras partes da mesma cadeia ou de outras cadeias, conduzindo à formação de hélices duplas.

O grau de cobertura da superfície de HOPG foi analisado para concentrações mais elevadas de ssDNA, mostrando uma rede densa, com zonas onde a superfície de HOPG está completamente descoberta, figura 10B. Muitos dos poros existentes dentro da camada de ssDNA não eram suficientemente largos para deixar exposta a superfície de HOPG após uma possível re-hidratação do substrato. figura 12 Imagens topográficas de ssDNA, obtidas em ar, com o modo MAC de AFM. O ssDNA foi imobilizado na superfície de HOPG, por adsorção durante 3 min, a partir duma solução de $5 \mu \mathrm{g} / \mathrm{mL}$ dsDNA em electrólito suporte de 0,1 M: (1) adsorção espontânea: (A) tampão acetato $\mathrm{pH}$ 5,3 e (B) tampão fosfato $\mathrm{pH}$ 7,0; (2) adsorção com potencial de $+300 \mathrm{mV}$, us. AgQRE: (C) tampão acetato pH 5,3 e (D) tampão fosfato pH 7,0.

\section{Efeito do pH na adsorção de dsDNA e ssDNA na superfície de HOPG}

O processo de adsorção de dsDNA e de ssDNA, com ou sem potencial aplicado, é directamente influenciado pela composição e pH do electrólito suporte, determinando o grau de cobertura e a robustez dos filmes de DNA adsorvidos no eléctrodo de HOPG.

Para poder compreender a influência exercida pelo pH da solução de electrólito suporte na preparação de filmes finos de DNA, foi estudada a adsorção de dsDNA e ssDNA na superfície do eléctrodo de HOPG para o pH 5,3, onde o DNA tem maior eficiência de ligação com as superfícies hidrofóbicas, e comparada com a adsorção a pH fisiológico de 7,0.

Os filmes finos de dsDNA revelaram uma cobertura reticulada da superfície de HOPG. As moléculas de dsDNA organizaram-se numa camada semi-compacta, espalhada uniformemente sobre o eléctrodo, e moléculas de dsDNA sobrepostas, figura 11. As experiências com potencial aplicado mostraram, em especial para o $\mathrm{pH} 7,0$, uma forte interacção lateral entre as hélices adjacentes de dsDNA, causando uma conden- 
figura 13 (A, B) Imagens topográficas em três dimensões, e secções transversais obtidas ao longo das linhas brancas nas imagens, da superfície de HOPG modificada por filmes:

(A) finos e (B) espessos de dsDNA, obtidas em ar, com o modo MAC de AFM. O filme fino de dsDNA foi preparado aplicando um potencial de adsorção de +300 mV, us. AgQRE, durante $3 \mathrm{~min}$, ao eléctrodo de HOPG mergulhado numa solução de $60 \mu \mathrm{g} / \mathrm{mL}$ dsDNA em tampão fosfato 0,1 M,pH 7,0. O filme espesso de dsDNA foi preparado por evaporação a partir duma solução de $37,5 \mathrm{mg} / \mathrm{mL}$ dsDNA em tampão acetato 0,1 M, pH 4,5.

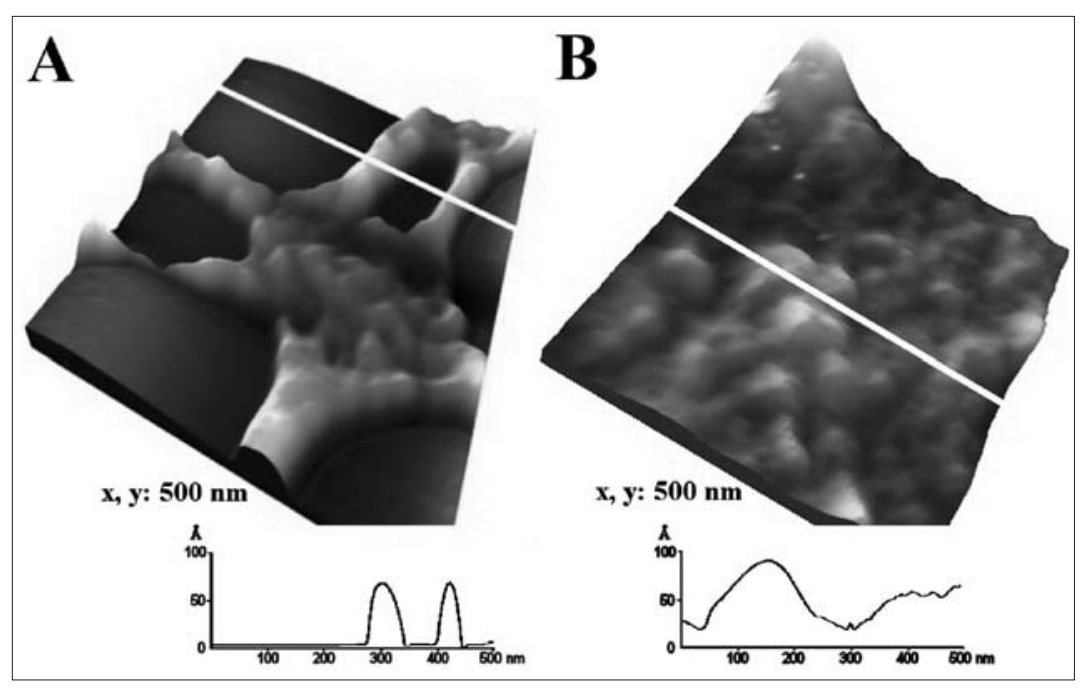

de HOPG e das interacções DNA-DNA. O método de adsorção com controlo de potencial aumentou a solidez do filme de ssDNA em ambos os pHs.

\section{Morfologia da superfície de HOPG modificada por filmes finos e espessos de dsDNA}

A estrutura e o grau de cobertura da superfície do eléctrodo representam um aspecto importante na construção de um biossensor electroquímico com DNA, que pode ser utilizado de maneira eficiente nas aplicações práticas. Com o objectivo de contribuir para o desenvolvimento e melhoria dos biossensores electroquímicos com dsDNA, utilizados na detecção e caracterização das interacções de fármacos e de proteínas com - DNA, foi analisada a morfologia da superfície de HOPG modificada por adsorção de um filme fino e de um filme espesso de dsDNA, sendo comparadas as diferenças estruturais e o grau de cobertura da superfície.

A superfície do eléctrodo de HOPG foi modificada pela adsorção de um filme fino de dsDNA, e as imagens de MAC modo AFM já descritas mostraram a organização do filme de dsDNA numa rede bidimensional não uniforme, figs. 9B, 11D e 13A. A camada de dsDNA apresentava poros que deixavam descobertas partes do eléctrodo.

Um outro método de imobilização de dsDNA na superfície de HOPG foi por evaporação completa do solvente de uma solução concentrada de dsDNA colocada na superfície do eléctrodo de HOPG, resultando na formação de um filme espesso. Depois da desidratação completa do gel de dsDNA, o eléctrodo ficou coberto por um filme de dsDNA visível a olho nu. As imagens obtidas com o modo MAC de AFM mostraram a superfície de HOPG completamente coberta por um filme uniforme de dsDNA, figura 13B. A topografia do filme apresentava núcleos de tamanhos muito variados, de $3 \mathrm{~nm}$ até $50 \mathrm{~nm}$ em altura e de $50 \mathrm{~nm}$ a $400 \mathrm{~nm}$ de largura a meia altura.

As redes bidimensionais de dsDNA, geradas na superfície do eléctrodo de HOPG na formação dos filmes finos de dsDNA, definem regiões activas diferentes na superfície do sensor electroquímico. Devido à existência de poros na camada de dsDNA, na superfície de HOPG aparecem zonas que não ficam cobertas pelo filme molecular, figura 14A. Estas zonas descobertas da superfície do eléctrodo de HOPG podem actuar como sistemas de microeléctrodos com dimensões nanométricas e micrométricas. Neste contexto, as propriedades do eléctrodo e das moléculas de dsDNA adsorvidas na superfície condutora podem levar a aplicações muito interessantes, pois podem ser utilizadas como matrizes de biomateriais para ligar e estudar outras moléculas de interesse, como proteínas e fármacos.

As modificações do dsDNA, devido à interacção específica com proteínas e fármacos, são em geral detectadas pela modificação do comportamento electroquímico dos componentes do dsDNA duzidos, em consequência das ligações múltiplas com a superfície hidrofóbica 
imobilizado, nomeadamente as bases purínicas [6]. No entanto, certos fármacos apresentam uma forte adsorção, na superfície dos eléctrodos de carbono, e podem ter actividade electroquímica, tal como o dsDNA danificado. O maior problema que se põe na utilização de eléctrodos modificados por um filme fino de dsDNA é a cobertura incompleta do eléctrodo, que permite a difusão das moléculas de fármacos do interior da solução para a superfície descoberta do eléctrodo, seguida pela adsorção nãoespecífica na superfície do eléctrodo, além da interacção com o filme de dsDNA, figura 14B. Este processo conduz a duas contribuições para o sinal electroquímico, o sinal proveniente do fármaco electroactivo adsorvido na superfície e o sinal do dsDNA modificado ou danificado.

A adsorção não-específica do fármaco no eléctrodo não ocorre nos biossensores electroquímicos de filme espesso de dsDNA, devido à cobertura completa do eléctrodo, figura 14C. A resposta do biossensor é determinada apenas pela interacção do dsDNA com as moléculas intercaladas na espessa camada de filme, figura 14D, sem contribuição do fármaco existente no interior da solução [6].

\section{Conclusão}

A investigação efectuada por AFM contribuiu para uma melhor compreensão dos processos de adsorção, nucleação e crescimento de filmes moleculares finos ou espessos de guanina, dsDNA e ssDNA, obtidos sobre uma superfície condutora.

A guanina adsorveu na superfície do substrato de HOPG, cobrindo uniforme e completamente o eléctrodo com um filme molecular muito estável e resistente, e a adsorção pôde ser controlada utilizando métodos electroquímicos de deposição.

As imagens obtidas com o modo MAC de AFM indicaram que o dsDNA e o ssDNA adsorvem espontaneamente na superfície do eléctrodo de HOPG, mostrando um processo de adsorção muito rápido. Estas moléculas apresentam a capacidade de auto-organização no suporte sólido, a partir da solução, formando redes bidimensionais que cobrem o eléctrodo de maneira uniforme. A interacção das moléculas com a superfície hidrofóbica de HOPG induziu à sobreposição das moléculas e a interacções intra e intermoleculares. Os filmes de ácidos nucleicos são mantidos imobilizados na superfície de HOPG por intermédio de interacções não-covalentes, tais como pontes de hidrogénio, empa- cotamento das bases, forças electrostáticas, forças van der Waals e interacções hidrofóbicas. A formação de redes de dsDNA e de ssDNA com grande resistência e estabilidade mecânica foi obtida por adsorção assistida electroquimicamente.

Os resultados obtidos e apresentados ao longo deste trabalho mostram claramente a importância da compreensão do processo de adsorção dos ácidos nucleicos na superfície dos eléctrodos e da avaliação correcta de todos os factores que influenciam a resposta do biossensor electroquímico com DNA. O desenvolvimento de biossensores com DNA deve incluir uma caracterização adequada da morfologia das moléculas adsorvidas e da cobertura da superfície do biossensor, obtida pela escolha apropriada da concentração da solução, do pH e dos métodos de deposição.

Relativamente a perspectivas futuras, a capacidade das técnicas de AFM de permitirem efectuar a observação das amostras in situ, no decorrer das experiências electroquímicas, poderá permitir a análise directa, em tempo real, de vários processos na superfície dos biossensores electroquímicos com DNA, incluindo a interacção do DNA com fármacos ou proteínas.

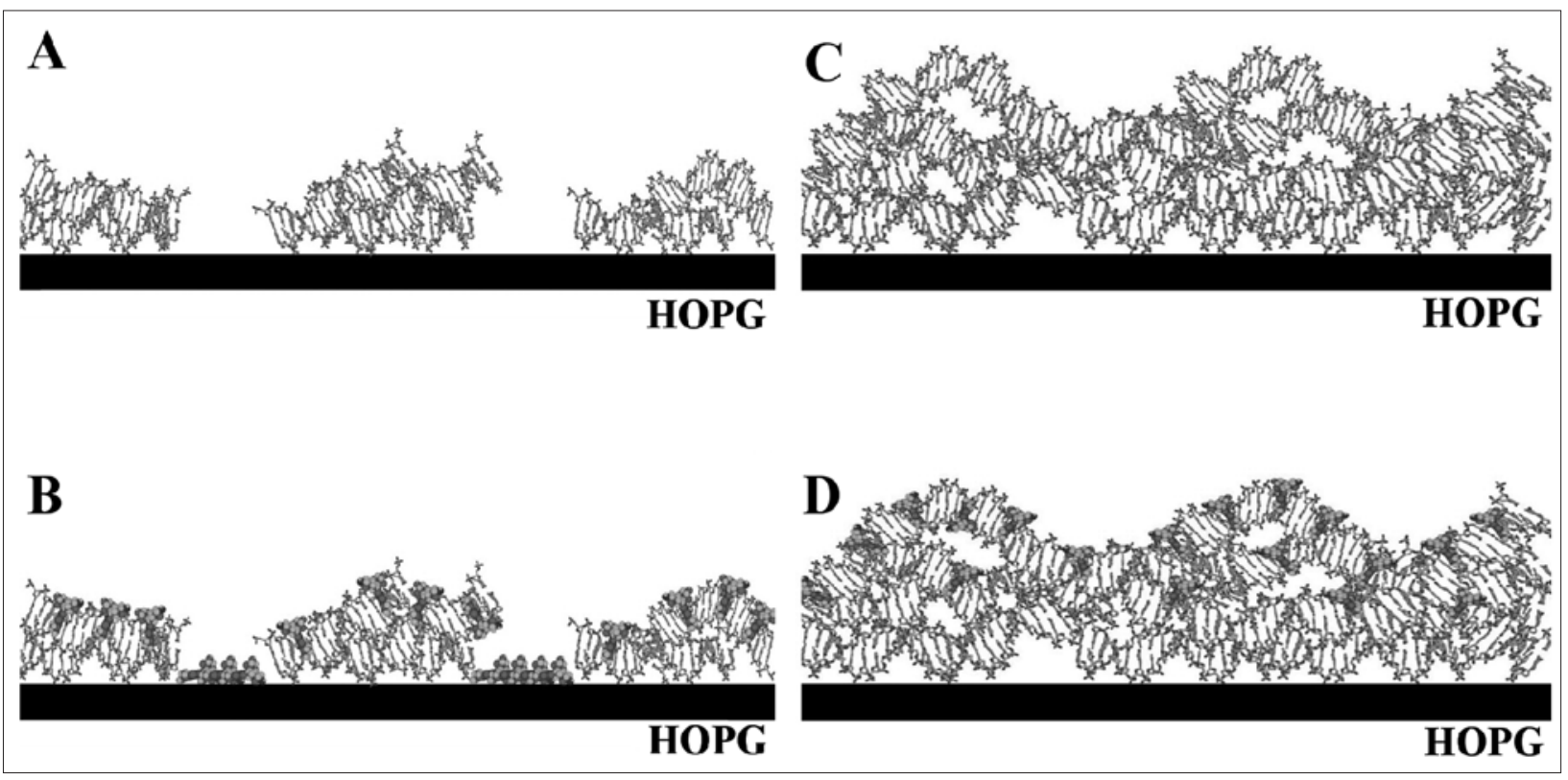

figura 14 Modelos esquemáticos da adsorção de: (A, C) dsDNA na superfície de HOPG, com a formação de um filme (A) fino e (C) espesso; (B, D) um fármaco na superfície de HOPG modificada por um filme (B) fino e (D) espesso de dsDNA. 


\section{Agradecimentos}

Financiamentos pela Fundação para a Ciência e Tecnologia (FCT): Bolsa de Pósdoutoramento SFRH/BPD/14425/ 2003 (A.-M.C.P.), POCTI (co-financiado pelo FEDER) e ICEMS (Research Unit 103).

\section{Bibliografia}

1. W. Saenger, in Principles of nucleic acid structure, Springer Advanced Text in Chemistry, C. R. Cantor (ed.), Springer-Verlag, New York, 1984.

2. N. C. Seeman, Annu. Rev. Biophys. Biomol. Struct. 27 (1998) 225.

3. I. Willner, Science 298 (2002) 2407.

4. A. M. Oliveira Brett, S. H. P. Serrano e J. A. P. Piedade, in Comprehensive Chemical Kinetics, Applications of Kinetic Modeling, vol. 37, R. G. Compton, G. Hancock (eds.), Elsevier, Oxford, UK, 1999, capítulo 3, 91.
5. A. M. Oliveira Brett, in Comprehensive Analytical Chemistry. Biosensors and Modern Specific Analytical Techniques, L. Gordon (ed.), Elsevier, Oxford, UK, 2004, em impressão.

6. A. M. Oliveira-Brett, M. Vivan, I. R. Fernandes e J. A. P. Piedade, Talanta 56 (2002) 959.

7. M. Miles, Science 277 (1997) 1845.

8. D. A. Bonnell e B. D. Huey, in Scanning Probe Microscopy and Spectroscopy. Theory, Techniques, and Applications, 2. ${ }^{a}$ edição, D. A. Bonnell (ed.), Wiley-VCH, New York, 2001, capítulo 2, 7.

9. R. Wiesendanger, in Scanning Probe Microscopy and Spectroscopy: Methods and Applications, R. Wiesendanger (ed.), Cambridge Univ. Press, Cambridge, 1994.

10. W. Han, S. M. Lindsay e T. W. Jing, Appl. Phys. Lett. 69 (1996) 4111.

11. A. M. Oliveira-Brett e A.-M. Chiorcea, Electrochem. Commun. 5 (2003) 178.

12. A. M. Oliveira Brett e A.-M. Chiorcea, Langmuir 19 (2003) 3830.
13. A. M. Oliveira Brett e A.-M. Chiorcea, Biochemistry 63 (2004) 229.

14. J. D. Watson e F. H. C. Crick, Nature 171 (1953) 737.

15. R. Franklin e R. G. Gosling, Nature 172 (1953), 156.

16. V. N. Soyfer e V. N. Potaman, in Triplehelical Nucleic Acids, R. C. Garber (ed.), Springer-Verlag New-York, Inc., New-York, 1996.

17. A.-M. Chiorcea e A. M. Oliveira-Brett, Bioelectrochemistry 55 (2002) 63.

18. A.-M. Chiorcea e A. M. Oliveira Brett, in ASI NATO on Scanning Probe Microscopy: Characterization, Nanofabrication and Device Application of Functional Materials, P. Vilarinho (ed.), 2004, em impressão.

19. A. M. Oliveira Brett e F. - M. Matysik, J. Electroanal. Chem. 426 (1997) 95.

20. I.A. Rebelo, J.A.P. Piedade e A.M. Oliveira-Brett, Talanta, 2004, 63 (2004) 323.

21. H. G. Hansma, I. Revenko, K. Kim e D. E. Laney, Nucleic Acids Res. 24 (1996) 713.

\section{Actualidades Científicas}

\section{Mais Pistas para o Ciclo do Azoto}

De acordo com estudos recentes, o passo de nitrificação do ciclo do azoto conhecido apenas em microorganismos, ocorre também em algumas plantas. 0 ciclo do azoto é mediado por interacções entre plantas, animais e microorganismos. Algumas plantas são fundamentais, porque possuem bactérias com capacidade para reduzir o azoto atmosférico a amónia, o passo conhecido como fixação de azoto. No passo de nitrificação, o azoto orgânico é convertido a nitrito e a nitrato. Este processo é mediado por microorganismos, principalmente bactérias.

Investigadores da Universidade de Wales, Swansea, descobriram que a nitrificação também ocorre em algumas plantas, em particular na espécie Hippocrepis comosa, um membro da família das leguminosas com a capacidade de fixação de azoto [Hipkin et al., Nature (2004) 430, 98]. Esta planta acumula ácido 3-nitropropiónico (3-NPA) nas suas folhas, um composto altamente tóxico que protege a planta de herbívoros. Quando as suas folhas estão a morrer, a planta degrada o 3-NPA a ácido 3-oxopropanóico, formando nitrito e nitrato. Quando as folhas caem, estes iões re- gressam ao solo. O trabalho revela que o nitrato pode ser depositado no solo, mesmo na ausência de microorganismos nitrificadores. Os investigadores, adiantam no entanto que a extensão da nitrificação através desta via é várias ordens de grandeza mais baixa que a da via microorganismos, não deixando de ser significativo o facto de ela existir (adaptado de Chemical \& Engineering News (2004) 82 (27), 6).

Helder Gomes

\section{Nanotubos Macios}

Investigadores da Universidade de Basel, Suiça, sintetizaram nanotubos poliméricos capazes de serem preenchidos com substâncias solúveis em água. Estes materiais poderão encontrar aplicações na libertação controlada de fármacos e na síntese inorgânica. A equipa, liderada por Wolfgang P. Meier, desenvolveu um novo método, fácil e eficiente, para a preparação de nanotubos macios preenchidos com água, estáveis mecânica e quimicamente, com diâmetros de cerca 50 nm e comprimentos de até dezenas de micrómetros (Grumelard et al., Chem. Commun., (2004) 1462). Estas estruturas são baseadas em blocos de copolímeros auto- organizados, que podem ser fixos permanentemente por polimerização cruzada. Os tubos têm um volume interno grande e podem ser preenchidos com qualquer espécie solúvel em água.

Os macromonómeros que se auto-organizam para formar os nanotubos são copolímeros tri-bloco ABA. Os dois blo$\cos A$ são constituídos por poli-2-metiloxoazolina (PMOXA), hidrofílico, e o bloco $B$ consiste em poli-dimetilsiloxano (PDMS), hidrofóbico. A equipa de investigadores sintetizou os copolímeros por polimerização catiónica com abertura do anel da 2-metiloxoazolina em PDMS activado. Os blocos PMOXA tem grupos terminais hidroxilos, que permitem funcionalização com ácido metacrílico. Em solução aquosa, os macromonómeros tri-bloco formam estruturas supramoleculares que podem ser químicamente cruzadas por polimerização dos grupos ácidos metacrílicos. Para verificar que a superfície interna dos nanotubos é hidrofílica, encapsularam carboxifluoresceína (um corante fluorescente solúvel em água) nos nanotubos e fizeram a sua observação por microscopia de fluorescência.

Helder Gomes 